\title{
Understanding Water-Energy-Food and ecosystem interactions using the nexus simulation tool NexSym
}

\author{
Elias Martinez-Hernandez ${ }^{1, *}$, Matthew Leach ${ }^{3}$, Aidong Yang $^{4}$ \\ ${ }^{1}$ Department of Chemical Engineering, University of Bath, Bath BA2 7AY, UK \\ ${ }^{2}$ Department of Engineering Science, University of Oxford, Oxford OX1 3PJ, UK \\ ${ }^{3}$ Centre for Environmental Strategy, University of Surrey, Guildford GU2 7XH, UK \\ *Corresponding author:
}

Email: eliasiq2008@gmail.com, e.martinez.hernandez@bath.ac.uk

Tel: +44 (0)1225383488

\begin{abstract}
The water-energy-food (WEF) nexus concept highlights the importance of integrative solutions that secure resource supplies and meet demands sustainably. There is a need for translating the nexus concept into clear frameworks and tools that can be applied to decision making. A simulation and analytics framework, and a concomitant Nexus Simulation System (NexSym) is presented here. NexSym advances the state-of-the-art in nexus tools by explicit dynamic modelling of local techno-ecological interactions relevant to WEF operations. The modular tool integrates models for ecosystems, WEF production and consumption components and allows the user to build, simulate and analyse a "flowsheet" of a local system. This enables elucidation of critical interactions and gaining knowledge and understanding that supports innovative solutions by balancing resource supply and demand and increasing synergies between components, while maintaining ecosystems. NexSym allowed assessment of the synergistic design of a local nexus system in a UK eco-town. The design improved local nutrient balance and meets $100 \%$ of electricity demand, while achieving higher carbon capture and biomass provisioning, higher water reuse and food production, however with a remarkable impact on land use.
\end{abstract}

Keywords: nexus, water, food, energy, modelling, simulation, local production systems

\section{Introduction}

Water, energy and food are essential to sustain the development of our society. By 2030, water demand is expected to increase by $40 \%$ [1], and energy by 50\% [2] and food also by $50 \%$ [3] in respect to 2010 levels, mainly due to the increasing population and higher standards of life in developing countries. Under the stressors of climate change, progressive urbanisation and resource scarcity, it is becoming urgent for governments, industries and organisations to secure access to water, energy and food. The corresponding provisioning systems are strongly interrelated [4], with approximately $15 \%$ of global water withdrawals used for energy production [5] and 70\% for food production [6], while about 3\% of global electricity is required for water provision [7] and 6\% for food production [6]. The Water-Energy-Food (WEF) nexus 
concept was presented at the 2011 Bonn Conference as an approach that can support the realisation of Sustainable Development Goals, by reducing trade-offs and encouraging synergistic integration across sectors to achieve WEF security for human well-being with high efficiency levels, while ensuring ecologically sustainable use of resources [8].

The design, analyses and policies for the operation and planning of WEF production and preservation of ecosystems are usually addressed separately [9]. Tackling resource issues of the WEF nexus needs a systems view to couple human and natural systems in order to identify sustainable solutions [10]. Several studies have contributed to this coupling and mainly focused on the development of qualitative frameworks and from a policy perspective [11]. In practice, any decision will require first quantification of nexus interactions and analysis in terms of resource implications and ecosystems impact [12]. Identifying critical interactions is also important to leverage synergies that help to balance trade-offs. The motivation for this work is to develop a framework and a tool for integrated resource assessment, accounting for integration within and across WEF subsystems, ecosystem and consumption components that interact in a local system.

Studies approaching the nexus have been presented using various methods, tools and frameworks. Some of the first studies perform accounting and analysis for two-sector linkages (e.g. water-energy [13], food-energy [14]); for example, the SPAtial and Temporal NEXus Water Energy (SPATNEX-WE) model addresses the water-energy nexus comprehensively [15]. Studies have also been carried out for specific production systems (e.g. tomatoes production [16]). But tools capable of addressing any production systems and all the three nexus components in conjunction are needed to enable more comprehensive assessments. Table 1 shows examples of these kind of tools with a wide variety of scale, scope, flexibility and analytical capability. WEF nexus analyses have so far been mostly applied at large spatial scales such as global [17], regional [18] or national level [19]. For example, the Global Biosphere Management Model (GLOBIOM) has been adopted which allows to consider global diversification of land uses [17]. Multi-Regional Input-Output modelling (MRIO) has been applied to study the WEF nexus in East Asia value chains [20]. The WEF Nexus Tool 2.0 is a scenario-based tool for guiding resource allocation at the country level for a given level of food self-sufficiency and a set of technologies, land uses and resource availabilities [19]. Addressing smaller scales, the WEF nexus has also been analysed for cities and urban environments from a resilience point of view [23]. One recent development is the Data Envelopment Analysis (DEA) Model to evaluate the WEF-Nexus input-output efficiency at the city level [24]. This model allows building a local index system from regional and national data, which is useful when local level data is scarce; but the framework does not deal with interconnections of WEF resources. At the household scale, an integrated model has been proposed to capture the interactions between WEF at the end-use level [29].

A key desirable feature of a nexus analytics tool is its ability to quantify and assess connections between different subsystems. Recently, a quantitative assessment framework has been proposed which considers the inter-sectoral consumption of WEF resources and calculates the variations in total consumption by a country depending on different demands and technology efficiencies [21], but it does not account for inter-sectoral synergies or ecosystem processes. 
The Multi-Scale Integrated Analysis of Societal and Ecosystem Metabolism (MuSIASEM) is an analytical framework that consolidates quantitative information about socio-economic metabolism into indicators at different hierarchical levels of the society, based on flows (energy, water, energy and money) and funds (land, population, work force and technological capital) [22]. Two of the more comprehensive and flexible tools in Table 1 are Climate, Land, Energy and Water Strategies (CLEWS) and the Platform for Regional Integrated Modelling and Analysis (PRIMA). CLEWS is a framework that integrates existing simulation tools using a modular structure which allows analysing interactions between interconnected sectors [25]. PRIMA features enhanced domestic resolution, individual sector models and a flexible, portable, and modular platform which facilitates its application to different types of analyses, regions and components [26]. A more exhaustive review of methods, frameworks and tools for nexus can be found in [27][9][11]. An interactive web-based platform for inter-model comparison of existing modelling tools has also been developed [28].

Table 1 Characteristics of existing Nexus tools and frameworks for integrated modelling and assessment

\begin{tabular}{|c|c|c|c|c|c|}
\hline Tool & $\begin{array}{l}\text { Modelling } \\
\text { Framework }\end{array}$ & Scale & System breadth & $\begin{array}{l}\text { Analytical } \\
\text { capability }\end{array}$ & Flexibility \\
\hline GLOBIOM [17] & $\begin{array}{l}\text { Dynamic } \\
\text { multiregional partial } \\
\text { equilibrium model }\end{array}$ & Global & $\begin{array}{l}\text { WEF nexus and other } \\
\text { interacting systems } \\
\text { such as ecosystems }\end{array}$ & $\begin{array}{l}\text { Geographically- } \\
\text { explicit and long- } \\
\text { term management } \\
\text { of global land uses }\end{array}$ & $\begin{array}{l}\text { Focused on land } \\
\text { uses }\end{array}$ \\
\hline $\begin{array}{l}\text { WEF Nexus Tool } \\
2.0[19]\end{array}$ & Input-output & National & $\begin{array}{l}\text { WEF nexus } \\
\text { components }\end{array}$ & $\begin{array}{l}\text { Scenario-based for } \\
\text { given food self- } \\
\text { sufficiency level } \\
\text { calculates nexus } \\
\text { resource flows and } \\
\text { interactions, and } \\
\text { greenhouse gas } \\
\text { (GHG) emissions }\end{array}$ & $\begin{array}{l}\text { Focused on food as } \\
\text { entry point and } \\
\text { Qatar country }\end{array}$ \\
\hline $\begin{array}{l}\text { MuSIASEM } \\
{[22]}\end{array}$ & $\begin{array}{l}\text { Input-output, nested } \\
\text { hierarchical view of } \\
\text { the economy }\end{array}$ & $\begin{array}{lr}\text { Aggregated } & \text { to } \\
\text { national or sub- } \\
\text { national level }\end{array}$ & $\begin{array}{lr}\text { WEF } & \text { nexus } \\
\text { components, } & \text { land, } \\
\text { economy, } & \text { human } \\
\text { capital } & \text { and } \\
\text { ecosystems } & \end{array}$ & $\begin{array}{l}\text { Accounting of } \\
\text { flows and funds and } \\
\text { their ratios as } \\
\text { indicators. GHG } \\
\text { emissions and land- } \\
\text { use }\end{array}$ & $\begin{array}{l}\text { Adaptable to } \\
\text { various contexts }\end{array}$ \\
\hline CLEWS [25] & $\begin{array}{lr}\text { Integrates detailed } \\
\text { models } \\
\text { different tools }\end{array}$ & Regional & $\begin{array}{l}\text { Climate, Land, } \\
\text { Energy and Water }\end{array}$ & $\begin{array}{l}\text { Depend on the tools } \\
\text { used for the CLEW } \\
\text { assessment }\end{array}$ & $\begin{array}{l}\text { Depend on the tools } \\
\text { used for the CLEW } \\
\text { assessment }\end{array}$ \\
\hline $\begin{array}{l}\text { Quantitative } \\
\text { assessment } \\
\text { framework [21] }\end{array}$ & $\begin{array}{l}\text { Input-output based } \\
\text { on Lontief matrices }\end{array}$ & National & $\begin{array}{ll}\text { WEF } & \text { nexus } \\
\text { components }\end{array}$ & $\begin{array}{l}\text { Scenario-based, } \\
\text { accounting of nexus } \\
\text { resource } \\
\text { consumption and } \\
\text { interdependency } \\
\text { indicators }\end{array}$ & $\begin{array}{l}\text { Fixed defined } \\
\text { technologies and } \\
\text { interactions }\end{array}$ \\
\hline $\operatorname{DEA}[24]$ & $\begin{array}{l}\text { Data Envelopment } \\
\text { Analysis Model }\end{array}$ & Local (city level) & $\begin{array}{ll}\text { WEF } & \text { nexus } \\
\text { components }\end{array}$ & $\begin{array}{l}\text { input-output } \\
\text { efficiency }\end{array}$ & \\
\hline PRIMA [26] & $\begin{array}{l}\text { Integrates regional } \\
\text { climate, hydrology, } \\
\text { agri- culture and } \\
\text { land use, } \\
\text { socioeconomics and } \\
\text { energy systems } \\
\text { sector models }\end{array}$ & Regional & $\begin{array}{l}\text { WEF components, } \\
\text { economy, land use }\end{array}$ & $\begin{array}{l}\text { Climate change } \\
\text { related analyses and } \\
\text { costs, land use, } \\
\text { greenhouse gas } \\
\text { emissions }\end{array}$ & $\begin{array}{l}\text { Flexible, portable } \\
\text { and modular }\end{array}$ \\
\hline
\end{tabular}

There are several common deficiencies of the existing nexus tools. First of all, many of them handle the connections between the three elements of the nexus, but without the inclusion of the interaction between the ecosystems and the nexus. Furthermore, most of them are generally based on static models and do not account for dynamic changes in the ecological components and resource availability. This calls for further efforts to develop tools that can not only process 
existing time series of data but also simulate the varying environmental, ecological, technological and policy constraints that could change significantly the way WEF nexus components interact and consequently lead to different system outcomes. Such dynamic simulation is needed to support medium and long-term decisions that requires reliable knowledge of future behaviour of the system of concern. To enable the inclusion of a wide range of ecosystems into nexus modelling, an implementing software platform will need reusable and customisable models and a modular structure to provide flexibility.

Existing nexus tools can also be assessed in terms of the targeted scales. Compared to other scales, there are only a few studies addressing the production and consumption around the nexus at the local scale, yet it is at the local scale where actual implementation of technical or policy solutions tends to occur and where benefits or impacts are directly realised. Furthermore, the WEF nexus manifests in unique ways in different localities while global conditions may affect each location differently. Therefore, there is a need for a nexus tool based on local scale so that solutions are better tailored to local conditions and to make it easier to target synergistic techno-ecological interactions [30]. Using mathematical optimisation, the benefits of codesigning water, energy and food nexus components in locally integrated production systems for efficient use of available resources have been demonstrated [31]. This type of approaches from process systems engineering are suitable not only for design [32] but also for explicit modelling and analysis of nexus resource interactions.

Focusing on the local scale, the present research aims to contribute to integrated WEF nexus simulation and analytics by applying the techno-ecological synergy concept [30], [33], incorporating system dynamics, and modelling explicit direct exchange of resources between nexus subsystems beyond the accounting of inter-sectorial footprints. This paper extends and adapts our previous work to consider a wider range of component interactions, which could better balance resource trade-offs. Furthermore, it presents the further development of the conceptual approach into a practical software tool called the Nexus Simulation System (NexSym). NexSym allows to explore not only how parts of the nexus are affected by a change in another part, but also to evaluate key interactions that could be developed into synergistic integrations. The approach (comprising a conceptual framework and a modelling framework) and the software structure are described in the following sections, followed by a case study that demonstrates the capabilities of the NexSym tool.

\section{The Nexus Simulation System (NexSym)}

\subsection{Purpose and intended functions}

Local nexus interactions have so far received little attention from existing studies which focus more on basin, regional, country and even global levels. NexSym is a tool that targets on the local scale, by modelling co-located technological and ecological processes within a geographical scope where concerted decision making and implementation is possible. Therefore, NexSym is envisioned as a tool for simulating processes and their interactions in local production systems. The scope of modelling includes energy, water and food production and waste treatment as well as interacting components important for the WEF nexus such as 
ecosystems, consumption and other components of a local system. As distinctive features, NexSym aims to explicitly simulate synergistic interactions between subsystems and analyse the level of resource sufficiency and maintenance of ecosystem capacities to meet demands of a local population. More specifically, by combining user data inputs, predictive models and integrated outcome analysis as shown in Figure 1, NexSym is intended to enable nexus analytics at the component, nexus, and local system levels:

- At the ecosystem component level, simulations are to assess resources availability against ecological limits as well as the impacts of interactions with production processes and of ever changing environmental inputs. Alternatives for supplying a resource or service from the ecosystem (e.g. biomass from heathland or forest) can also be analysed. An ecosystem analysis would include the dynamic trends of ecosystem states and services, and scenarios with different climatic conditions or inputs from the technological components.

- At the technological component level, simulation of each production process is to quantify the material and/or energy flows according to the availability of local resources as well as the other input flows required. The corresponding wastes or emissions flows are also to be determined.

- At the nexus level, the effect of changing one part of the nexus on the other parts of the nexus and the impact on ecosystems and resource availability are to be analysed. Alternative schemes for integration between components within and across the nexus are also to be explored, as a distinctive feature of NexSym. NexSym aims to produce a nexus resource overview to quantitively reveal the nexus interdependency. Also, a contribution analysis of nexus resource use and supply by the various components can be performed to identify those parts in the system that consume excessive resources per unit of output, and those that could potentially help to balance surpluses and deficits.

- At the whole system level that encompasses WEF technological processes, ecosystem components and consumption, interactions that are useful to preserve ecosystems as the ultimate provider of resources can be analysed to determine what synergies, co-benefits, and trade-offs can lead to more sustainable solutions. Resource efficiency and sufficiency for meeting the demands, as well as the material and energy sources created or eliminated by changes in design, operation, planning and policies, can be analysed, and environmental impacts (in terms of emissions and wastes flows) quantified. 


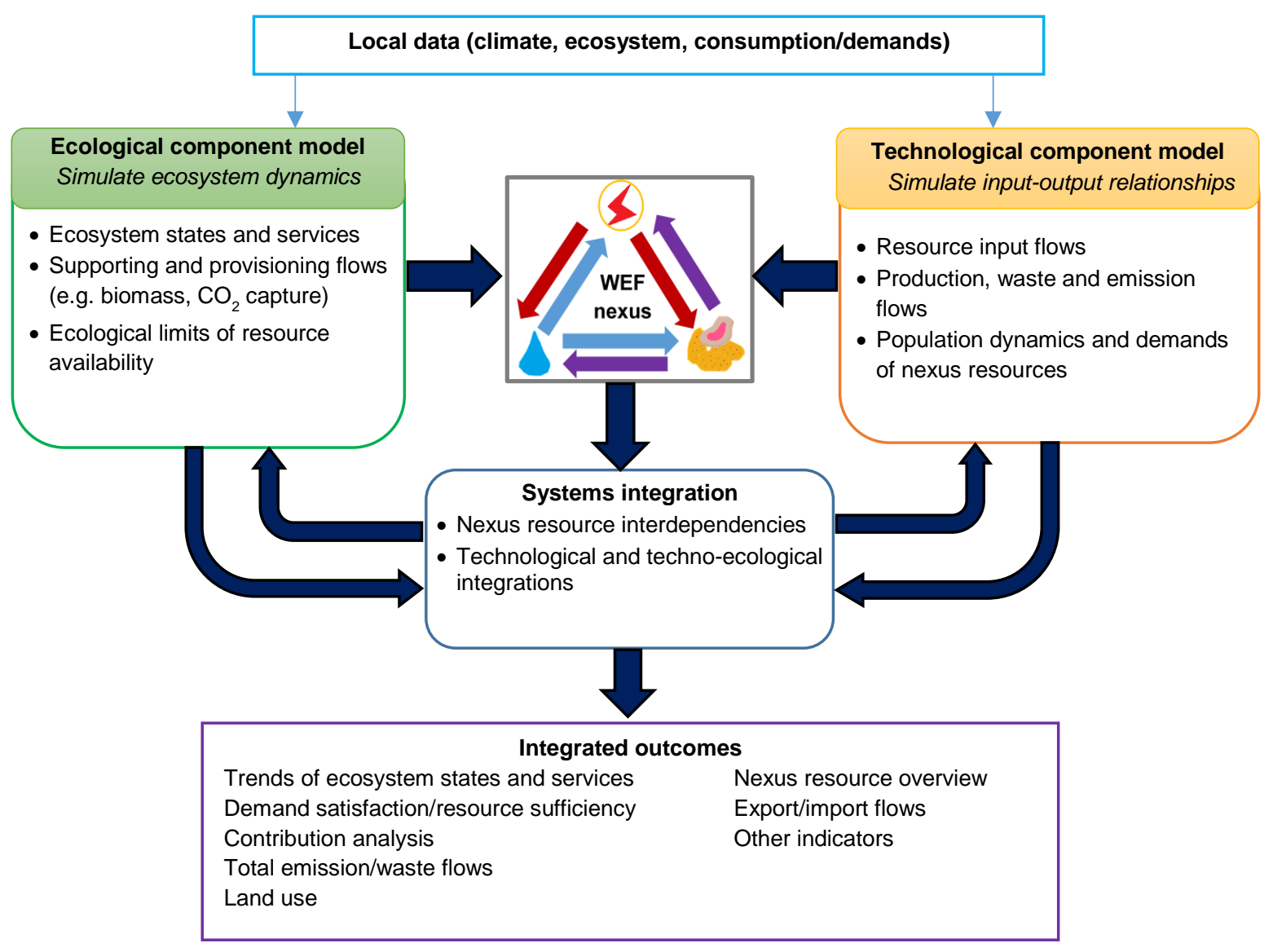

Figure 1 Intended input and output of NexSym.

The above expected functionality of NexSym is to be realised through a user-friendly simulation system that provides the following software features:

- Flowsheeting tools for building "virtual" interconnected WEF nexus systems

- Consolidated presentation of results facilitating analysis with different views;

- Incorporation of a customisable and expandable model library;

- Easy deployment and access by users.

The conceptual framework, modelling approach and software design and implementation that supports NexSym simulation capability are presented in the following sections.

\subsection{The conceptual framework}

Conceptually, the development of NexSym is supported by adapting a generic framework for modelling local production systems [30]. At the abstract level, a local system contains a number of inter-connected components. Each component in turn encompasses one or more processes, each of which transforms or generate flows and possibly changes internal states of the component. Different processes within or between components are connected by various flows. NexSym models a local WEF system with three different types of components (cf. Figure 2):

- Ecological components refer to natural or managed ecosystems such as forests or heathlands. These components contain ecological processes which affect the 
availability of basic resources such as nutrients, biomass and water. In turn, ecological processes provide ecosystem services in the form of flows of raw materials such as biomass for energy production. Captured through its internal states, an ecological component also contains elements of resource accumulation, such as the stocks of nutrient, moisture and carbon in soil; the quantification of the temporal changes in the states and their supporting role to the provision of ecosystem services requires dynamic models for simulation, as discussed later.

- Technological components are mainly man-made industrial and municipal facilities, include: a) production processes for converting raw materials from ecological components or external supply into product flows; b) waste treatment components such as water treatment plant, composting, etc.; and c) resource storage components. Both ecological and technological components may process environmental inputs such as rain, solar irradiation and wind into useful energy or material (e.g. potable water). Components interact with each other through resource flows, either as intermediate product, final product, wastes or treated discharges.

It should be noted that, although this work was primarily motivated by the need for assessing the supply of energy, food and water based on local (therefore often renewable) resources, the tool that has been developed can handle technological components fuelled by fossil resources in the same way as those by renewables, so as to enable the assessment of systems operating with hybrid inputs.

- Consumption components are considered to represent "sinks" of products and services, such as residential and commercial activities. A consumption component may be of a technological or an ecological nature, but it is different from the other two types of components in that it does not fulfil a function needed by other components, and merely offers a sink to a useful output and in some cases generates certain waste streams. As such, the primary role of a consumption component usually does not have a structure or sophisticated mechanism to be represented; its primary role is to represent a certain demand.

A techno-ecological view of a (local) WEF system is illustrated in Figure 2, which features interactions between energy production from biomass, food cultivation, water provision and wastewater treatment. These components depend on ecosystem services. Bioenergy production depends on biomass harvested, which affects the state of the ecosystem that produces biomass and therefore needs to stay within the ecological limits of the system so that its long-term capacity to provide and maintain certain service or function (e.g. biomass production) is not decreased. The relevant ecosystem may need nutrient recycling, which may be enabled by a technological component such as anaerobic digestion (AD) which at the same time can supply a nexus resource such as energy. This way, a synergistic techno-ecological integration can be established, and the impact of this integration on the WEF inter-dependency and the overall system performance can be analysed, for example to determine how much nutrient recycle the ecosystem can assimilate while maintaining its supporting states. It is important to capture the dynamics of feedback control loops like this (where more nutrient recycle generates more biomass) as they could potentially change the ecological limit for biomass harvesting as well as their resilience to other disturbances (e.g. excessive nitrogen deposition for heathlands [34]). 


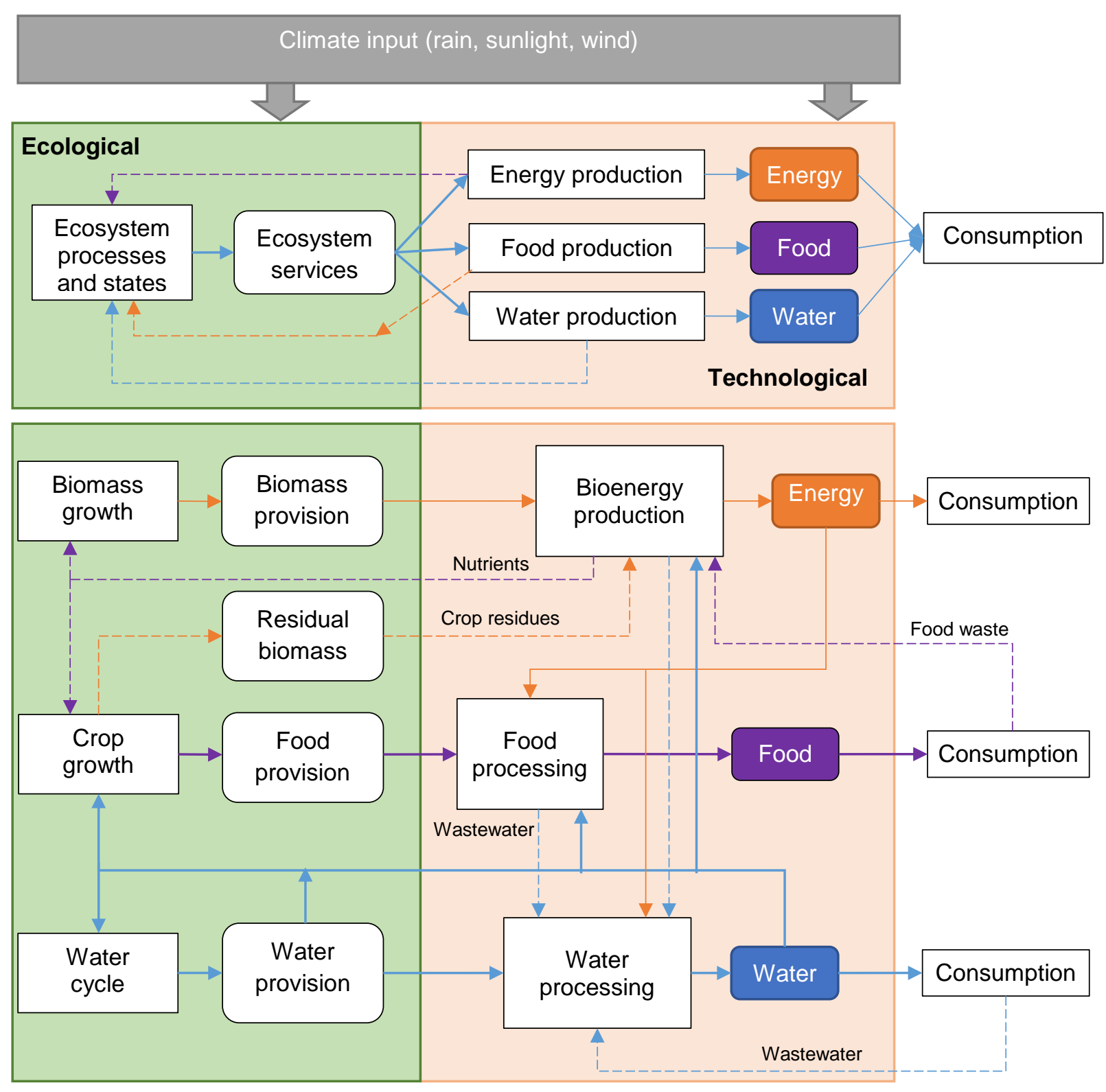

Figure 2 Illustrative techno-ecological view of water, energy, and food subsystem and their interactions.

In addition to techno-ecological integration and dynamics, examining existing and potential resource flows between specific system components allows detailed interactions and synergistic opportunities to be considered, as opposed to merely the depiction of interdependency between different WEF sectors. Looking at the system exemplarily shown in Figure 2, bioenergy production would create a new water demand required for steam generation and cooling as well as to form biomass slurry for AD. This is a direct interaction where water is needed for energy production. Besides, it also introduces a secondary link as AD generates a liquid waste stream requiring water treatment, thus energy subsystem provides an input of water to the water subsystem. Furthermore, the water treatment may produce some sludge that can be processed for energy production. While ecosystem components provide a set of services or functions, it should be noted that technological components can in fact be also multifunctional. For example, AD provides both energy generation as biogas and treatment of residues such as sludge and recovery of nutrients that can be directed for biomass or crop 
growth in the ecosystem, as shown in Figure 2. Wastewater treatment regenerates water from consumption, food processing and energy generation and recovers nutrients in the sludge as shown in Figure 2. Combined heat and power (CHP) does not only provide energy but also can also treat crop residues as shown by the crop flow in Figure 2. Similarly, food processing generates wastewater which can be input to the water processes, resulting in higher supply of treated water available for reuse.

While the above techno-ecological framework conceptually allows the important aspects and connections within a local WEF system to be captured, quantitative support to decision making needs to be built on mathematical modelling, which is presented next.

\subsection{The modelling framework}

The modelling framework that support NexSym simulations is a continuation of that presented in [30]. This framework clearly distinguishes between ecological and technological processes for modelling purposes, with dynamic models used primarily for ecological components and algebraic input-output models used for technical components. Human consumption is modelled according to a population dynamics curve.

The slow rate of ecological processes makes necessary to employ dynamic models to enable the tracking of ecosystem states for long-term planning. Therefore, an ecological component model is a system of differential equations of the form:

$$
\frac{d S_{i}}{d t}=F_{i}^{\text {in }}-F_{i}^{\text {out }}+G_{i}-C_{i}
$$

Equation 1

Where $S_{i}$ is the state or stock of resource $i$ in the ecosystem such as nitrogen or water content in soil, $F_{i}^{\text {in }}$ and $F_{i}^{\text {out }}$ represent input (e.g. fertilisation, rainfall) to and output (e.g. nitrogen volatilisation or water transpiration) from a given component (an ecosystem component in the case of Eq. 1), respectively; $G_{i}$ and $C_{i}$ are the generation and consumption rate of the resource (e.g. biomass growth or mortality), and $t$ is time. $G_{i}$ and $C_{i}$ can be a function of the ecosystem states, which allows determining ecological limits for extraction of resources such as nutrients and water. An example of using Equation 1 is to determine carbon capture ability of cultivated crops or ecosystems such as heathland (the detailed model for this is presented in [34]). Equation 1 is also used to model the water availability in soil as well as the variations in water level in aquifers. In the case of an aquifer, for example, the water level is the state, effectively captured rainfall is an input, and evapotranspiration and extraction are the outputs.

A technological component, where the dynamics is typically much faster than that of the ecosystem and hence a steady-state assumption can be imposed, is modelled as input-output relationships:

$$
F_{j}^{\text {out }}=F_{i}^{\text {in }} y_{i j}
$$

Equation 2

where $F_{j}^{\text {out }}$ is the outlet flow $j$ from a technological component which can be a product (e.g. electricity), waste or emission (e.g. wastewater or $\mathrm{CO}_{2}$ emission), $y_{i j}$ is the yield or efficiency 
factor of product $j$ per unit of input $i$ (e.g. MJ electricity per MJ of energy in biomass), and $F_{i}^{i n}$ is the inlet flow (e.g. biomass) to the technological component. The output can also be calculated from another output as:

$$
F_{j \prime}^{\text {out }}=F_{j}^{\text {out }} Z_{j^{\prime} j}
$$

Equation 3

where $F_{j \prime}^{\text {out }}$ is the outlet flow $j$ ' from a component which is proportional to outlet flow $j$ of the same component, and $z_{i j}$ is the factor relating the two outlet flows (for example, the amount of nitrogen flow out is proportional to nitrogen content in digestate). Note that Eq. 2 and 3 are calculated at each time step of the simulation and they will follow the dynamics of the inputs from ecological components or from climatic data inputs. That means the technological components, although characterised with a steady-state model, can still have time-variant outputs, as expected. The interconnectivity is enabled by a nomenclature that links component type, to the number and types of inputs and output required or produced by a component. For example, an ecosystem component produces biomass while anaerobic digestion or bioenergy component requires biomass, thus classifying the output and input flows as biomass allows making feasible matches between flows and both ends of the interconnection. This another key feature that provides NexSym with the flexibility to simulate different integration options by testing various ways of interconnecting components.

On the consumption side, a demand is either directly specified, or predicted by a consumption model. In particular, consumption by the residential sector are simulated through a human population (HP) in year $n$ estimated by the following dynamics:

$$
H P=a+\frac{b}{1+e^{(c-d \times n)}}
$$

Equation 4

where $\mathrm{a}$ is the initial population at year $0, \mathrm{~b}, \mathrm{c}$ and $\mathrm{d}$ are correlation coefficients This function then sets the dynamics of the food, energy and water demands as well as waste generation rates. The demands are calculated as:

$$
F_{k}^{d}=(H P) d_{k}
$$

Equation 5

where $F_{k}^{d}$ is the flow rate of product demand $k$ (e.g. water demand in a town), and $d_{k}$ is the typical per-capita consumption factor (e.g. water consumption per person per day). Similarly, the amount of wastes produced are calculated as:

$$
F_{w}^{e}=(H P) e_{w}
$$

Equation 6

where $F_{w}^{e}$ is the flow rate of emission $w$ (e.g. wastewater, household waste), and $e_{w}$ is a typical per-capita waste generation factor (e.g. kg of waste per person per year).

The connectivity between system components is captured by linking corresponding input and output flows. For example, if the output flow of resource i from an ecological component (as 
in Equation 1) is to become an input flow of a technological component (as in Equation 2), the following connectivity equation applies:

$$
F_{i}^{\text {out }}=F_{j}^{\text {in }}
$$

Equation 7

where $i$ has to be identical to $k$ to indicate an input and an output with the same nature, for example electricity. Similarly, a waste flow from a consumption component (as in Equation 6) can become an input flow to an ecological component (as in Equation 1):

$$
F_{i}^{i n}=F_{w}^{e}
$$

Equation 8

where again $i$ and $w$ need to match physically. When such a connection is established, the change in the demand by the consumption component, e.g. through the increase in local population (cf. Equation 5) will eventually affect the state $S_{i}$ of the technological system (as in Equation 1), through the corresponding change in waste generated (as by Equation 6), the connectivity (by Equation 8), and the dynamics of the technological component (by Equation $1)$.

While equations 1-8 offer a generic modelling approach to these different types of system components, models accommodating further details can be adopted in specific studies, which is supported by the software design and implementation of the NexSym tool.

\subsection{Software design and implementation}

Implementation of the framework discussed in the previous section into NexSym is achieved by adopting a modular and object-oriented approach for developing an expandable software tool. The structure of the software and the properties of object classes are illustrated in Figure 3. 


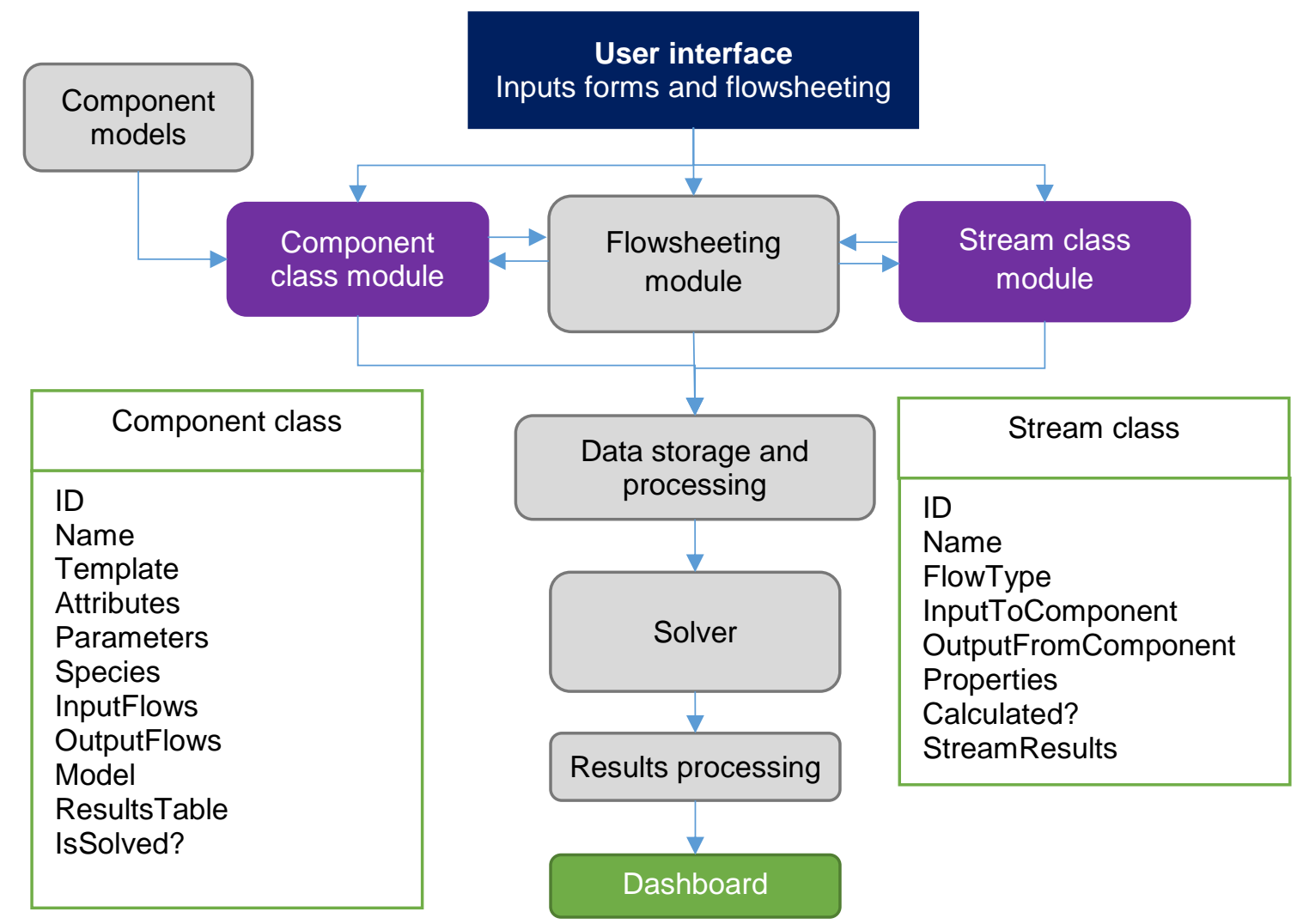

Figure 3 Structure of the nexus simulator NexSym and the class modules defining the Component and Stream objects.

The software platform is based on Excel spreadsheet and Visual Basic for Applications (VBA). NexSym uses VBA Input Forms for the user to input specifications of the system and its components. A component class and a stream class are defined to contain the process models and the input and output flows for each component. The flowsheeting module manages the user interface (shown in Figure 4) with the tools for the user to select components and connect them through streams. This module also manipulates the addition, deletion and reconnection of components and streams. All the user specifications and information about connectivity of the system flowsheet are processed and recorded in spreadsheets by the data storage and processing module. The component models can then be solved sequentially after the user specifies required parameters by the solver module. This module reads the model, model type and parameters. Subsequently, it runs a Runge-Kutta method for solving differential equations for modelling dynamics in ecological components, and computes the input-output relationships in the models for technological components. The solution provides results for every time step and the results are then stored in component templates and stream tables, which is the function of the results processing module. The component templates are spreadsheets where the model equations, the parameters and solutions for a given component are stored. The stream tables contain the calculated rates of all the flows in the flowsheet. The results processing module is also at the core of formatting and collecting data for nexus analytics and to present outcomes in a results dashboard. 


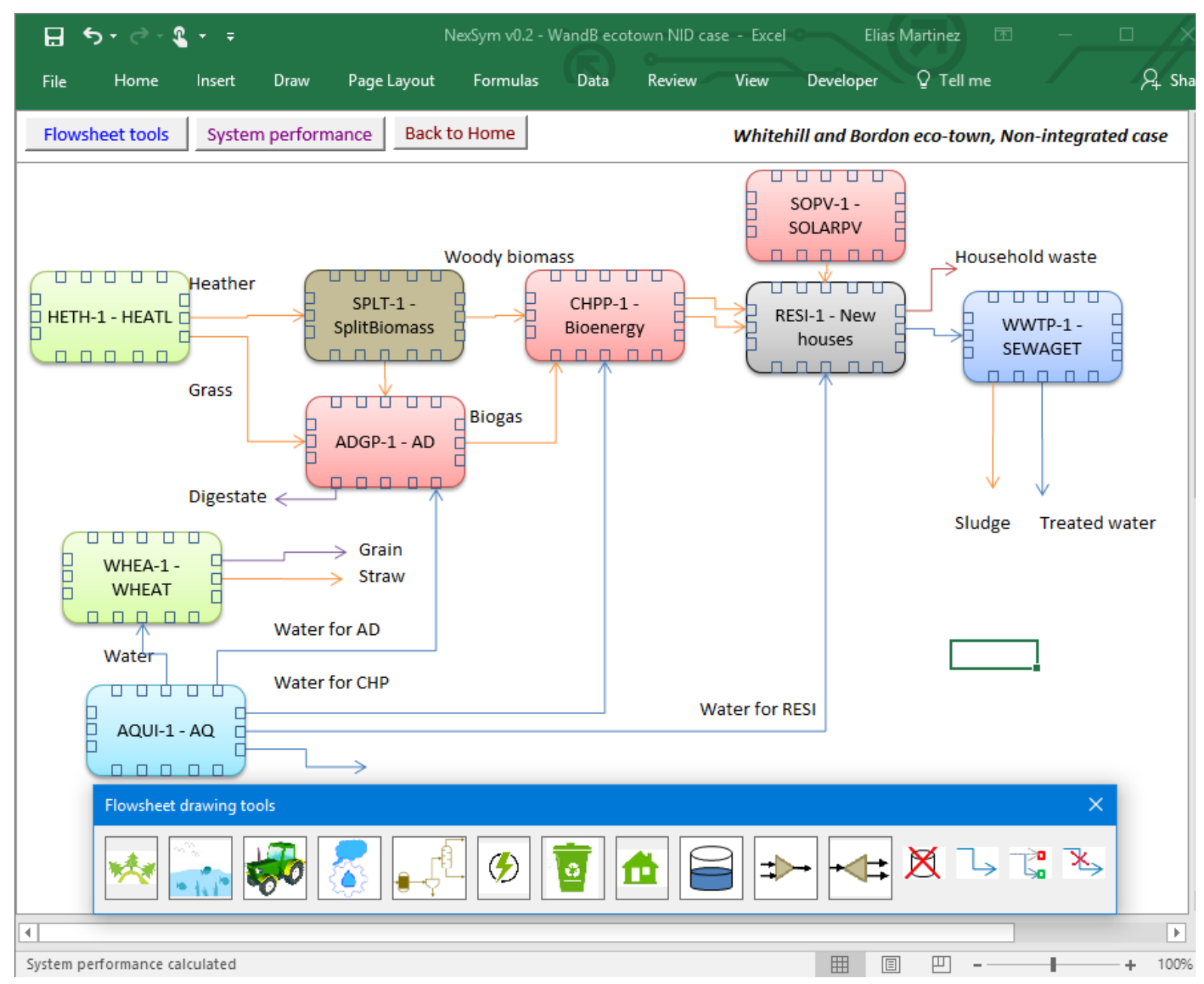

Figure 4 The user interface of NexSym.

\subsection{Using and extending NexSym}

The general steps to use the nexus simulation tool consist of:

1. Defining system level parameters such as location and monthly climatic data (rainfall, solar irradiation, wind speed, average daily temperature). As land is a critical resource in any techno-ecological system, the user should specify the amount of land available for ecosystems, residential, agricultural, industrial and other purposes. The user is also asked to define the overall temporal scope of the simulation (e.g. 30 years) and the global time step size for recording and reporting intermediate results.

2. Once the system level and simulation parameters have been specified, the user moves on to the flowsheet (i.e. the component-flow diagram) to draw the virtual local production system. The user should specify parameters for each of the components, which will be solved automatically once all the required inputs are in place. To model recycle loops a recycling ratio can be assigned initially in the component generating the resource to be recycled, which is then tuned until an optimum value is found, within the limitations of the ecosystem or technological components involved in the loop. The 
recycling flow is then calculated by the known outlet flow from the source component $i$, the recycling ratio and the recovery fraction of the material recovered downstream by a component $j$. This allows analysing the dynamic effects of techno-ecological interactions into resource availability and the level of recycle that can maintain ecosystem states and services.

3. Activating the results processing module which consolidates all the results into tables and plots for the dashboard.

Through the dashboard, the user can browse results consolidated by NexSym, by accessing the following views:

- Nexus overview containing i) a Nexus diagram with the system level flows between the subsystems of the nexus; ii) a Sufficiency diagram showing the level of demand satisfaction or sufficiency achieved by the local system; and iii) a Component distribution plot showing the contribution of each component to resource flow usage and supply;

- Ecosystem analysis showing the land use percentages, the dynamics of the supporting states and ecosystem services of the system;

- Supply-demand balance showing separate plots of the dynamics of supply and demand of energy, water and nutrient by nexus and consumption components.

- Wastes and emissions from the production and consumption components including $\mathrm{CO}_{2}$ emissions, wastewater, household waste and other wastes depending on the process.

As such, the dashboard provides a comprehensive insight into the performance not only of the nexus itself but also its supporting ecosystem states and services and the whole local production system. It enables to quantitatively visualise the outcomes of operational or structural changes in the system and the effects of component interactions and changes in the demands by the consumption components. The results can also be used to generate further indicators of interest (outside the current NexSym tool) to inform about the effects of decision making by planners, designers, and local governments, investors and the local population.

The modular design of the software allows expanding the existing model library through component spreadsheet templates and making use of the component and stream object definitions. In principle, introducing a new component model involves (i) creating a new spreadsheet template and VBA user input form with all relevant variables and parameters (ii) code the data transfer, model solution and results processing in VBA, (iii) if the model is for a new type of component, a new pre-drawn shape. Detailed procedures on expanding the model library are presented in the NexSym advanced user guide, available from the authors. Application of NexSym demonstrating its capabilities is illustrated in the following section.

\section{Nexus analysis in a local system using the NexSym tool}

In this section, we present a case study to illustrate the application of NexSym, particularly with respect to its role in assessing synergistic designs, by the following steps: 
(1) introducing the settings of the case study, including the objectives and the specific system components studied for the selected locale (Section 3.1);

(2) presenting simulation results of a system without synergistic design (Section 3.2); and

(3) updating the assessment by incorporating several synergistic connections between system components (Section 3.3)

At the end of this section, further developments of the simulation tool are discussed.

\subsection{Characterisation of the case study}

NexSym was used to simulate and analyse a system comprising components considered for the Whitehill and Bordon eco-town in the UK as part of a re-development plan. The plan considers building 3350 new houses; the local production system studied here is designed to partially or fully satisfy the energy, food and water needs of the corresponding population. Thus, several ecosystem, water, energy, food and waste treatment components would be required to meet such needs. The initial flowsheet of the system is shown in Figure 4.

\subsubsection{Objectives of the study and local system specifications}

The spatial scope of the study included the re-development land available which includes residential, industrial and ecosystem lands. The ecosystem components of interest are the heathland areas ( 2000 ha) surrounding the eco-town residential area and areas feasible for agricultural activities ( $~ 50 \mathrm{ha})$. Location, land availability and climatic data user specifications are shown in Figure 5. The temporal scope is of 50 years, which is a scale suitable to observe changes in ecological components due to the impact by the technological components. The global time step was set at 1 year.

The main objective is to analyse the effects of the various components of the local production system and their interactions and synergies on the level of demand satisfaction achieved and on ecosystem services and supporting states. For this purpose, the following two scenarios are analysed:

1. Non-integrated design (NID): Analysing nexus without synergetic integrations.

2. Synergistically integrated design (SID): Analysing nexus with components highly integrated through exchange of resources. 


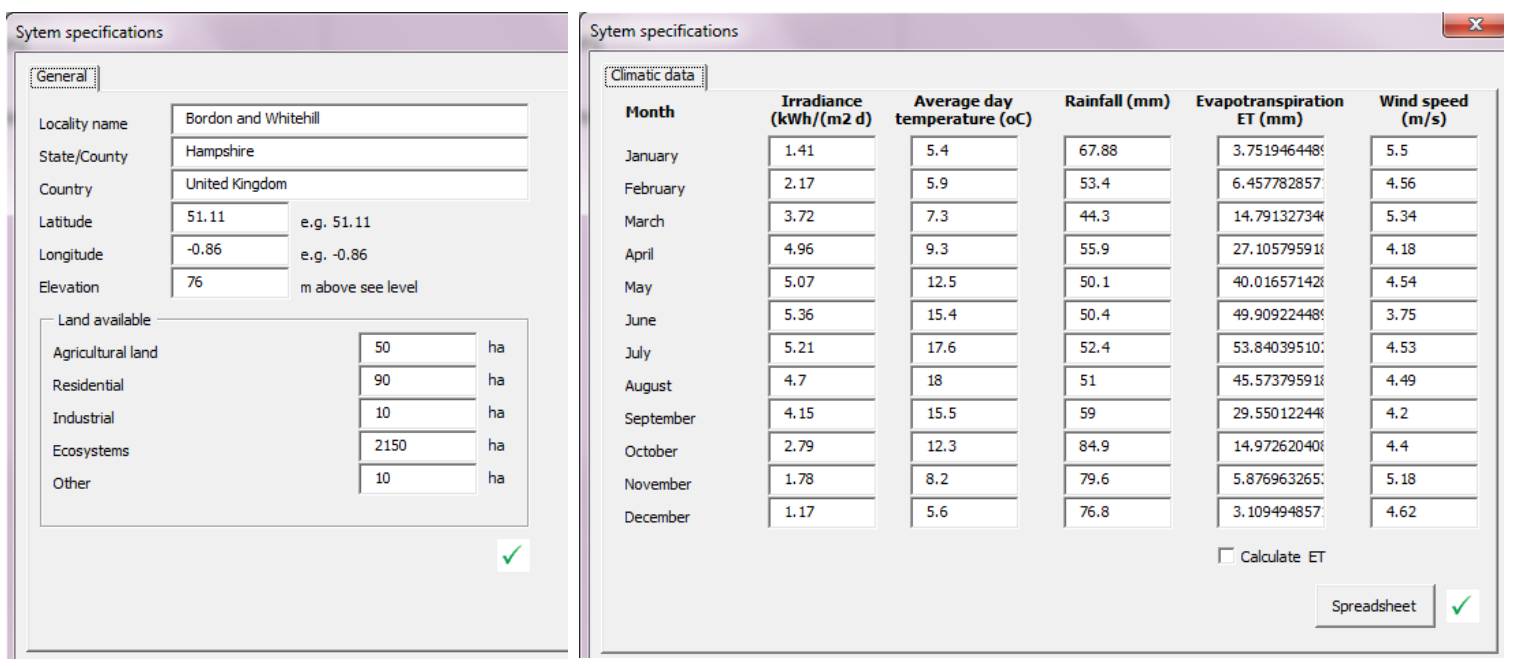

Figure 5 System specifications including location, land available and climatic data for the case study in NexSym.

\subsubsection{Local system components}

The local system under study comprises components which are shown in Table 2 along with the main parameters required for simulation. These specifications were based on the detailed information available from the eco-town planning documents. It should be noted that some of these parameters may vary with time and changes of lifestyles of future generations, however this was not captured by the model in the case study. The main processes and flows as well as ecosystem services and states involved are described as follows.

Energy subsystem - It includes an anaerobic digestion (AD) plant, a combined heat and power (CHP) plant and roof mounted solar panels on the houses as technological components. The ecological component that provides biomass as an ecosystem service is the heathlands, which are also good absorbers of $\mathrm{CO}_{2}$ and excess nutrients but which may be under threat from the current environmental and management conditions due to grass-woody biomass competition [34]. Thus, the main supporting states to analyse are (i) the standing biomass in the heathland which is affected by the amount of biomass harvested and (ii) the nitrogen balance in the ecosystem. The heathland biomass includes heather and grass biomass. The biomass can be separated into woody (hard) and soft biomass. The woody biomass, with a higher heating value and a lower moisture, can go to the CHP plant while the soft biomass with a higher moisture and a lower heating value can be processed by the $\mathrm{AD}$ plant into biogas which can then be used in the CHP plant.

Water subsystem - It includes a wastewater treatment (WWT) plant as a technological component and the aquifer as an ecological component. The WWT plant treats the sewage water produced by the households. An aquifer supplies freshwater to the locality and introducing new processes may affect the water balance and this was modelled to track the water level as an ecosystem state.

Food subsystem - The potential production of wheat for local bread production was considered in the food subsystem. Energy, water and fertiliser requirements are estimated from a wheat 
growth model. The wheat component produces wheat and straw as residues (for which a fraction is left on the field). A food subsystem could also play a role of assimilating excess nutrients available in the local system.

Consumption - The new households are considered in this case as a consumption component which the overall production system should aim to serve by satisfying its energy, water and food demands.

Table 2 Local system component specifications for the simulated systems in the case study. NID: Non integrated system; SID: synergistically integrated system

\begin{tabular}{|c|c|c|}
\hline Component & NexSym component & Specifications \\
\hline Heathlands & $\begin{array}{l}\text { Vegetation ecosystem - } \\
\text { heathland }\end{array}$ & $\begin{array}{l}\text { Land use: } 1600 \text { ha } \\
\text { Cutting biomass rate: } 0.45 \\
\text { N recycling (SID case only): } 0.9 \\
\text { Other specifications according to [34]. }\end{array}$ \\
\hline $\begin{array}{l}\text { Residential } \\
\text { houses }\end{array}$ & $\begin{array}{l}\text { Consumption } \\
\text { Residential }\end{array}$ & $\begin{array}{l}\text { Number of houses: } 3350 \\
\text { Initial population: } 3000 \text { people } \\
\text { Land use: } 90 \text { ha } \\
\text { Water demand: } 0.166 \mathrm{~m}^{3} /(\text { person d) } \\
\text { Electricity demand: } 5.24 \mathrm{GJ} /(\text { person } \mathrm{y}) \\
\text { Heat demand: } 15 \mathrm{GJ} /(\text { person y) }\end{array}$ \\
\hline $\begin{array}{l}\text { Wastewater } \\
\text { treatment } \\
\text { (WWT) plant }\end{array}$ & $\begin{array}{l}\text { Water processing - } \\
\text { WWT plant }\end{array}$ & $\begin{array}{l}\text { COD removal efficiency: } 0.9 \\
\text { Sludge yield: } 0.4351 \mathrm{~kg} /(\mathrm{kg} \text { COD }) \\
\text { Land use: } 0.3 \text { ha }\end{array}$ \\
\hline $\begin{array}{l}\text { Roof mounted } \\
\text { solar panels }\end{array}$ & $\begin{array}{l}\text { Energy production - } \\
\text { Solar PV }\end{array}$ & $\begin{array}{l}\text { Nominal output: } 2 \mathrm{~kW} \\
\text { Panel surface: } 14 \mathrm{~m}^{2} \\
\text { Number of panels: } 3350 \\
\text { Panel efficiency: } 0.75\end{array}$ \\
\hline $\begin{array}{l}\text { Combined heat } \\
\text { and power } \\
(\mathrm{CHP}) \text { plant }\end{array}$ & $\begin{array}{l}\text { Energy production - } \\
\text { CHP plant }\end{array}$ & $\begin{array}{l}\text { Electrical efficiency: } 0.4 \text { (NID case), } 0.232 \text { (SID } \\
\text { case) } \\
\text { Thermal efficiency: } 0.45 \text { (NID case), } 0.568 \text { (SID } \\
\text { case) } \\
\text { Land use: } 0.2 \text { ha }\end{array}$ \\
\hline $\begin{array}{l}\text { Anaerobic } \\
\text { digestion (AD) } \\
\text { plant }\end{array}$ & $\begin{array}{l}\text { Energy production }-A D \\
\text { plant }\end{array}$ & $\begin{array}{l}\text { Volatile matter (VM) fraction in slurry feed: } 0.2 \\
\text { Biogas yield: } 400 \mathrm{~L} / \mathrm{kg} \mathrm{VM}) \\
\text { Methane volume fraction in biogas: } 0.6 \\
\text { Nitrogen loss: } 0.05 \mathrm{~kg} / \mathrm{kg} \\
\text { Land use: } 0.3 \mathrm{ha}\end{array}$ \\
\hline Aquifer & Water body-Aquifer & $\begin{array}{l}\text { Rainfall run-off fraction: } 0.3 \\
\text { Interception fraction by vegetation: } 0.2 \\
\text { Initial water level (depth from ground to water } \\
\text { table level): } 15 \mathrm{~m} \\
\text { Thickness: } 90 \mathrm{~m} \\
\text { Transmissivity: } 300 \mathrm{~m}^{2} / \mathrm{d} \\
\text { Catchment area: } 200 \mathrm{ha}\end{array}$ \\
\hline $\begin{array}{l}\text { Wheat } \\
\text { production }\end{array}$ & Agriculture - Wheat & $\begin{array}{l}\mathrm{N} \text { fertilisation: } 150 \mathrm{~kg} / \mathrm{ha} \\
\text { Water irrigation: } 615 \mathrm{~m}^{3} / \mathrm{ha} \\
\text { Land use: } 50 \text { ha } \\
\text { Fraction of crop residue returned to soil: } 0.4\end{array}$ \\
\hline
\end{tabular}




\subsection{Analysing the WEF nexus in non-integrated design (NID)}

The non-integrated system was represented by a flowsheet in NexSym, displayed in the flowsheet area of the user interface shown in Figure 4. In this case, interactions through exchange of reusable resource flows between WEF subsystems were not considered, but the requirements of energy for water, water for energy and energy and water for food are predetermined as default parameters. The nexus overview plots generated by NexSym are shown in Figure 6 and Figure 7. Figure 6a depicts how the nexus manifests in the eco-town local system in a quantitative manner. The diagram shows the inter-sectorial energy and water flows at year 50. It can be observed that in this NID case, the food subsystem is more directly dependent on the other two nexus subsystems. Although water and energy are in this case not dependant on any input from the food subsystem, any changes in the food subsystem will impact on the other two by changing water and energy usage in the nexus.

The level of self-sufficiency achieved by the system at steady state is shown in Figure $6 \mathrm{~b}$. Steady states for electricity and heat supply was achieved at year 20, for water at year 13 and for nutrient at year 33. In this paper, self-sufficiency indicates the level of demand satisfaction by the local system from available local resources, for example $80 \%$ self-sufficiency means $80 \%$ is produced and supplied from the local system and the remaining $20 \%$ would need to be imported from the grid electricity. It is suggested that the system can achieve self-sufficiency in electricity, water and nutrient demand. However, there is deficit of heat while excess exists for water and nutrient. This means that resources are being wasted, or need to be exported outside of system boundaries which may or may not be realistic. Therefore, improvements are needed for a balanced system that promotes circularity of water and nutrient resources within the local system while increasing the level of heat sufficiency.

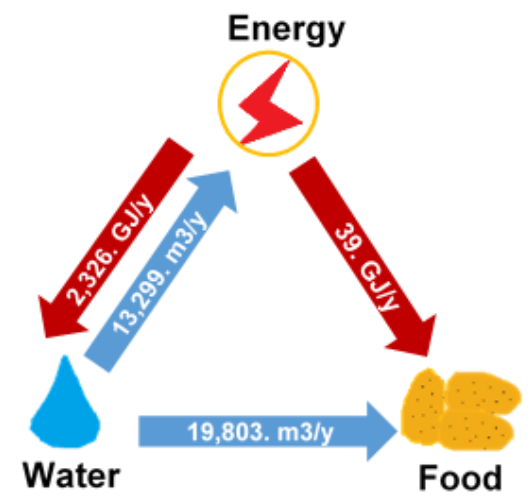

a)

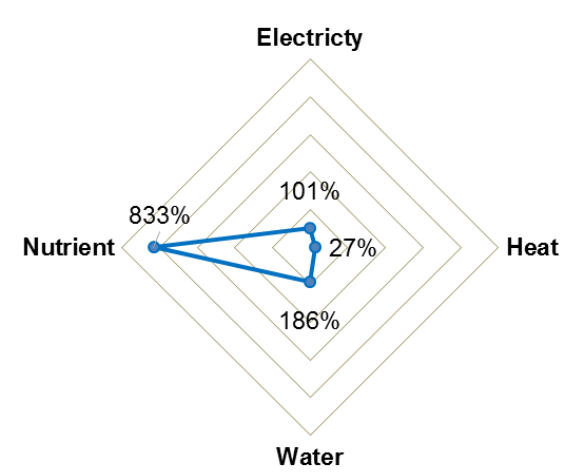

b)

Figure 6 a) Nexus diagram and b) sufficiency diagram generated by the NexSym tool.

In order to devise options for balancing the demand by local population and technological processes with the supply by local production processes only, a contribution analysis can provide additional insights as shown in Figure 7a. Any deficits between demand and supply are then calculated as imported flows, while surpluses are exported or waste flows. Energy in 
the nexus is mainly consumed by the water treatment plant and the aquifer components (in the latter case, electricity for pumping) and in a minor proportion by the wheat component (mainly for grain drying and storage). The water use in the nexus is mainly by the wheat component (for irrigation), followed by the AD plant (for the feed slurry) and the CHP plant (for steam generation and cooling). The wheat cultivation is now the only consumer of nutrients. Analysing the supply of energy, food and water by nexus components, it can be observed that CHP plant and roof mounted solar panels contribute with $75 \%$ and $25 \%$ of the total local energy generation, respectively. Water can be mainly supplied by the aquifer (54\%) and the treated water from WWTP (46\%). Nutrients from heathland biomass and from the sewage sludge are recovered by the $\mathrm{AD}$ plant and this is the only supplying component.
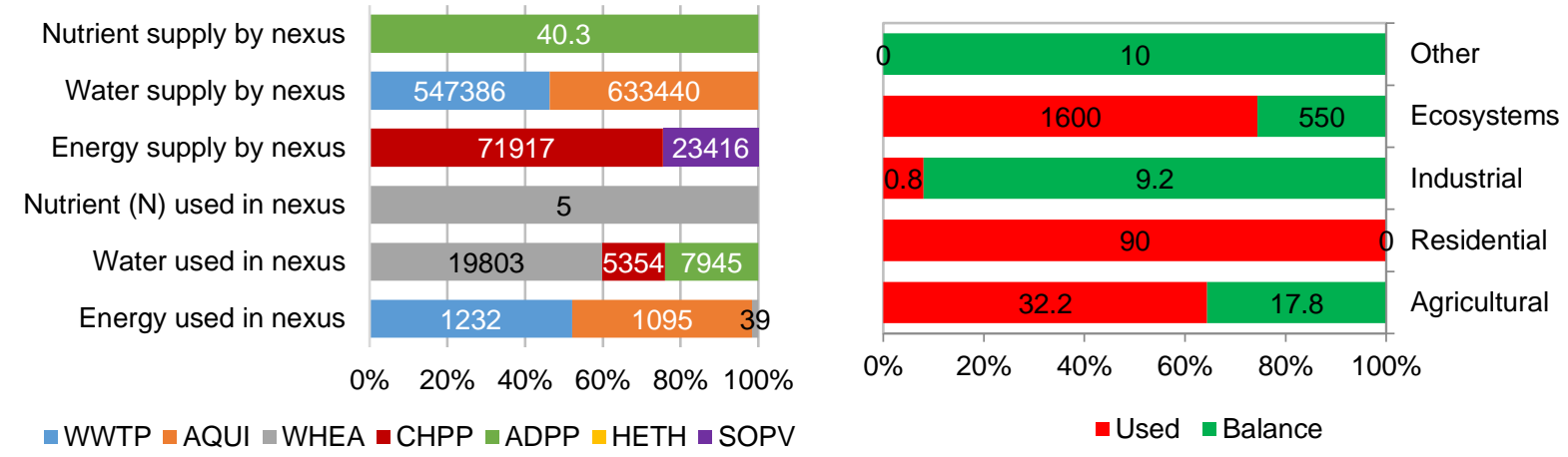

Figure 7 a) Distribution plot of a) water, nutrient and energy use and supply by the nexus components (not including consumption by residential component), and b) land use. Energy includes both electricity and heat.

An ecosystem analysis is helpful to establish ecological limits and ensure supporting states and services are maintained for a sustainable system. The system can produce enough wheat for local bread demand using $64 \%$ of the available agricultural land. Land use by other components were within the corresponding land availability as shown in Figure $7 \mathrm{~b}$. Figure 8a shows the dynamic results of the heather biomass and water level states. The biomass in the heathland is stabilised after 20 years at around $6500 \mathrm{~kg} / \mathrm{ha}$. The water level in the aquifer decreases slightly by about $0.3 \%$, thus the system is still within the ecosystem limits. Figure $8 \mathrm{~b}$ shows the water abstraction from the aquifer in million $\mathrm{m}^{3}$ per year, the rate of $\mathrm{CO}_{2}$ capture by the heathland and the wheat and the direct $\mathrm{CO}_{2}$ emissions. $\mathrm{CO}_{2}$ capture was found to more than offset direct emissions from the local production system, thus leading to a carbon neutral system and even with some excess of supply of carbon capture as ecosystem service. The dynamics of energy, nutrient and water supply and demands as well as emissions basically followed ecosystem and population dynamics.

So far, NexSym results showed that the system observes ecosystem limits for the nexus but there is excess of nutrient supply and deficit of heat. To address these issues, structural changes could be introduced by forming new interaction links of flows between nexus components. This is analysed as the synergistically integrated design (SID) case in the following section. 

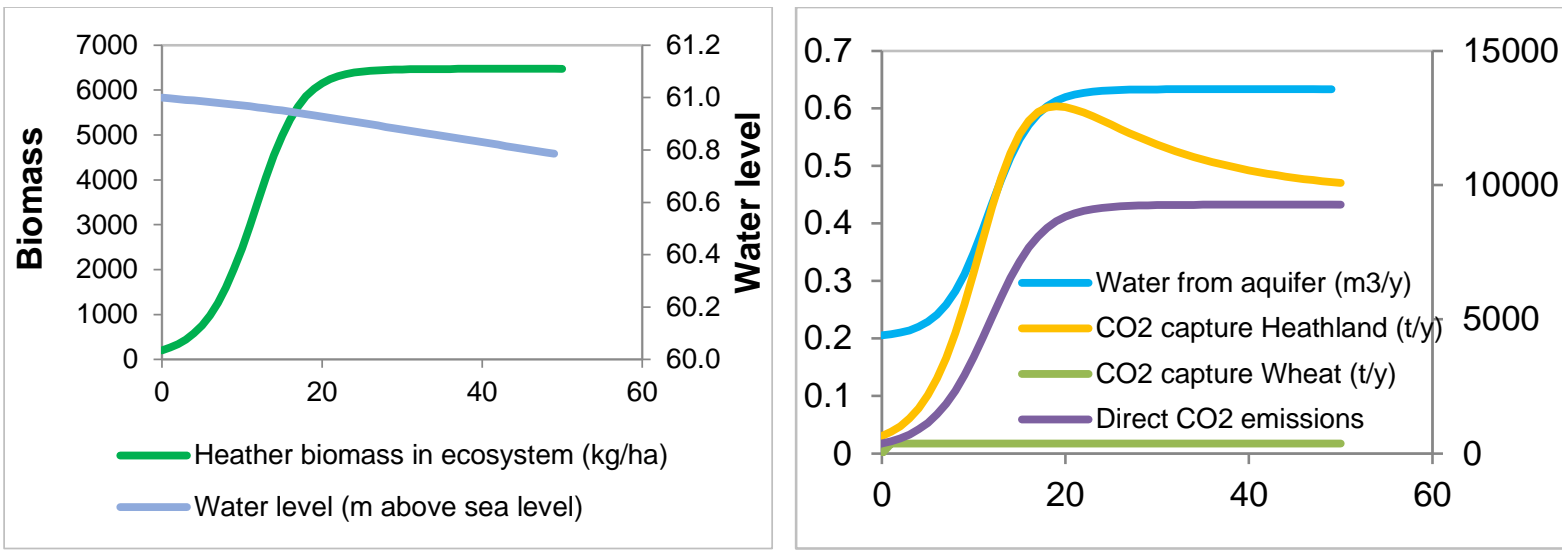

Figure 8 Dynamics of ecosystem a) states and b) services as estimated by the simulation in the NexSym tool.

\subsection{Analysing the WEF nexus in synergistically integrated design}

The non-integrated design was evolved into the synergistically integrated design (SID) with the objective to balance the nutrient surplus and increase heat sufficiency while reusing treated water in the system. Developing such a design requires the use of a nexus approach to devise integration within and across the WEF nexus and ecosystems through resource exchange between technological components as well as between technological and ecological components. This may be achieved by following a systematic approach focusing on synthesis or design, such as the one recently proposed in [35]. With a focus on simulation, the role of NexSym is to offer assessment of effectiveness and implications of a synergistic design. In this particular example, NexSym allowed to simulate the system from the NID case by redirecting or adding stream flows to create new connections between components. Splitters are used to distribute the excess resources from a source component to the various sink components. The resulting simulated flowsheet is shown in Figure 9, which, compared to Figure 4, now contains synergistic connections between system components. 


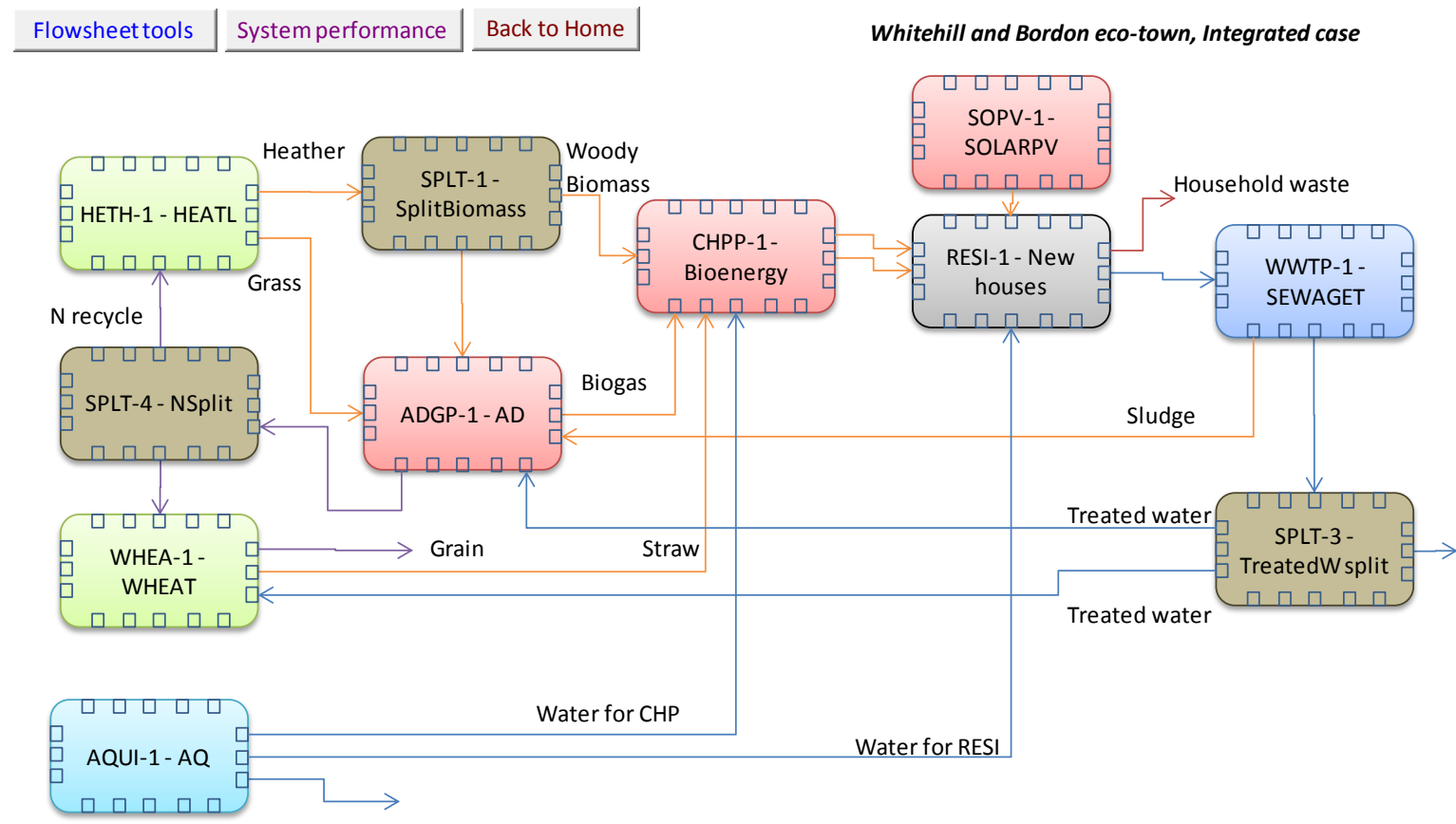

Figure 9 NexSym flowsheet of the synergistically integrated design of the local production system in the case study by using a nexus approach.

\subsubsection{Technological and techno-ecological integration}

Opportunities for improving resource use and recovery in the system arise when the system is integrated. The first of such integration involved using the sewage sludge from WWT for producing more biogas in AD plant and thus contributing to more energy sufficiency. Options for reusing treated water from WWT were also explored for AD which requires water for diluting solids and form a slurry to feed the bioreactor. Furthermore, a significant amount of fresh aquifer abstraction can be saved by using the treated water for wheat cultivation. A third opportunity arises by using wheat straw for energy production in the CHP plant.

Balancing the nutrient surplus, which was present in the NID case, requires supplying nutrients from the source to suitable sinks in the local production system. The only source is the AD which processes biomass and sewage sludge, while the sinks for using nutrients are the heathland and wheat cultivation components. Re-direction of the surplus nutrients leads to new techno-ecological synergies between these components as shown in Figure 9. Heathland can absorb the nutrients recovered in the AD that were initially in the harvested biomass, while allowing a higher biomass generation and harvesting rate to maintain the ecosystem [34]. Therefore, the higher biomass flows due to recycling of $90 \%$ of nutrients allows increasing energy production in the AD and CHP plants. Although the amount of nutrient supply is also increased in the system, this is balanced by the increased capacity of the heathland to absorb such nutrients. To absorb the remaining nutrient surplus, the amount of wheat cultivated is increased until the nutrient supply and demand in the system become balanced. The current model used in the case study does not capture the wider impact of wheat cultivation, e.g. on ecosystem services such as carbon fixation by the land. However, this can be addressed by extending the model to include additional states (e.g. stored carbon) and associated flows. 
Thus, the loop of "heathland-AD-Heathland", the path of "AD-Wheat-CHP" and treated water reuse are potential synergistic integrations which may lead to an improved local production system. These new measures however will also change the interactions within the local WEF nexus, therefore it is desirable to use NexSym to assess the consequences.

\subsubsection{System performance and impact on nexus interactions}

The integration of the various components in the local system creates new direct and indirect nexus interactions, which are analysed. Results from the NexSym dashboard are shown in Figure 10. The impact on the overall nexus interactions can be observed in Figure 10a which shows that the energy and food subsystem have become more dependent on water due to the increase in wheat cultivation and biomass processed in energy components. However, the system performance is improved in terms of sufficiency (Figure 10b). Noticeably, both nutrient balance and higher heat sufficiency are achieved while reducing the surplus water (mainly treated water). These improvements stem from the channelling $64 \%$ of the surplus nutrient (nitrogen) to heathland and the rest to wheat cultivation, as shown in Figure 10c. Another noticeable change is the increase of heat sufficiency from $27 \%$ (in NID) to $51 \%$ (in SID) (Figure 10b), with CHP now providing $82 \%$ of the energy generated in the system (Figure 10c). This is because the ecosystem service of biomass production by the heathland is enhanced by the application of recycled nitrogen to the heathland.

Regarding the impact on nexus interactions, the energy use by food components increases, mainly due to the corresponding increase in wheat cultivation. However, the energy use for water subsystem is not significantly increased, due to the rather moderate dependency of water on energy. On the other hand, the water usage for energy increases, as additional water flow is now required in $\mathrm{AD}$ and $\mathrm{CHP}$ plants for processing the increased biomass flow from the heathland. An additional simulation was run (not shown here) to determine the amount of wood chips that need to be imported to achieve $100 \%$ heat supply. Results showed that $5000 \mathrm{t} / \mathrm{y}$ would be required in the CHP with an adjusted electrical and heat efficiencies of $13.9 \%$ and $67 \%$, respectively.

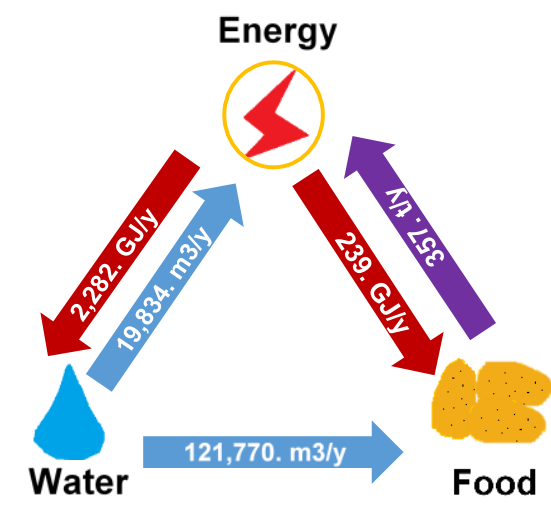

a)

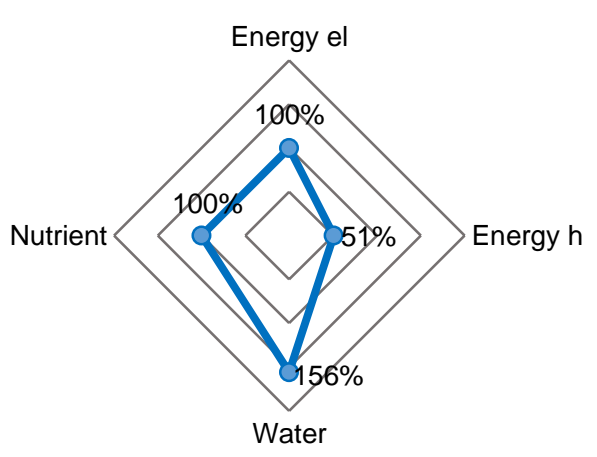

b) 


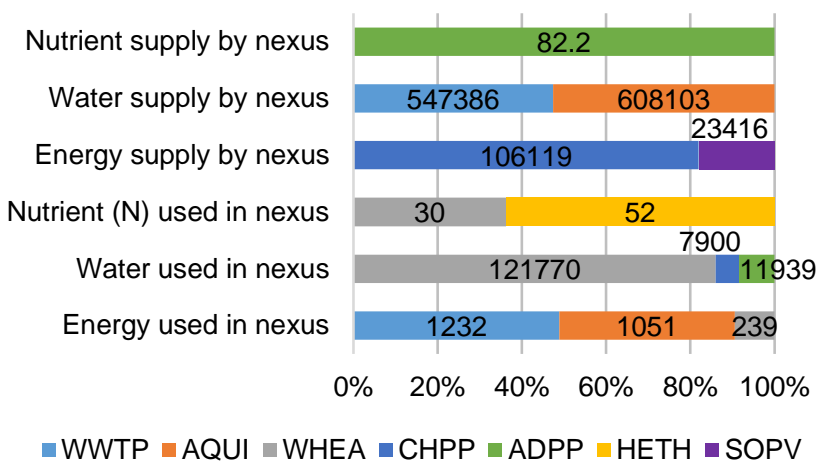

c)

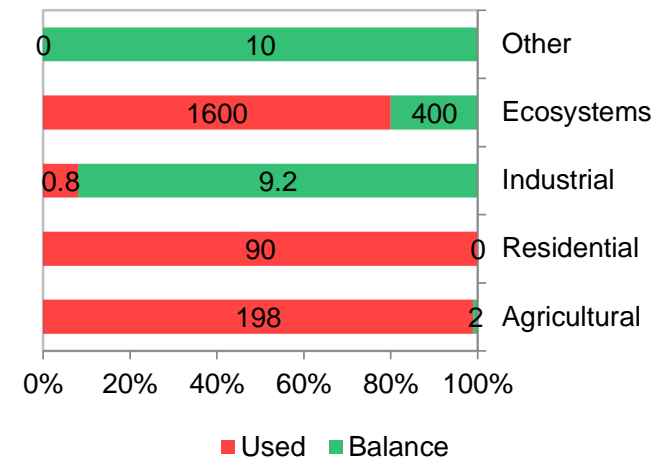

d)

Figure 10 NexSym simulation results for the integrated design of the system in the case study showing a) the nexus diagram, $b)$ the sufficiency diagram, $c$ ) the resource use and supply by the nexus components and d) the land use in the system.

In the SID case, the water usage for food production also increases significantly along with expanded wheat cultivation. However, treated water reuse by wheat cultivation and anaerobic digestion allows water excess to decrease from 186\% (Figure 5) to 156\% (Figure 10). It is worth noting that usually water cannot be fully balanced when treated (waste) water is considered as part of the available water flow produced by the local system along with fresh water input. This is because water quality is an important factor, which prevents a water source to match with a sink which requires a quality higher than that of the sink. This is the case of water for households which required high purity not achieved by the WWT, thus the treated water is not suitable for this purpose and needs to be discharged to the environment (as surplus) when not fully absorbed by other sinks. Although not simulated here, the ecotown is also exploring the option of having separate water systems, one for potable water which is the one requiring high quality and the non-potable water used for washing, toilets and so on. This way the water in the system could be further balanced.

In the food subsystem, the balancing of nutrients implies an increase on wheat production and now surplus wheat can be exported. However, the land required for this would need the repurposing of 100 ha of land (out of a total of 150 ha of land to be managed as an ecosystem according to the eco-town plan) for agricultural purposes (Figure 10d). Furthermore, water would be lost out of the local system as moisture in the wheat exported. However, this would be less critical in this specific local system analysed here, where the water availability is relatively high and wheat water content is relatively low, in contrast to the case of tomatoes grown in the arid regions of Spain, for example [16].

The case study also showed that multiple services can be quantified of an ecosystem component, such as biomass production and $\mathrm{CO}_{2}$ capture of heathland. Therefore, the simulation tool can potentially offer analyses of the trade-off between multiple ecosystem services as the consequence of design decisions [34], although this aspect is not explicitly presented in this current case study. 


\subsection{Future developments of the nexus simulator}

Through analysis of NexSym simulation results, useful informing for decision making can be derived for the nexus situation in a particular locality. This is helpful especially because the nexus can manifest differently depending on local conditions. As a tool primarily for studying local systems, NexSym requires sufficient details of a locale to allow meaningful assessments to be carried out. When location-specific data is unavailable, the adoption of generic values for missing parameters could introduce inaccuracies to its output. Therefore, engagement with researchers and local communities to develop datasets specific to local contexts is crucial for the successful application of such a tool.

Also, although arguably less critical at the local scale, the tool currently does not account for spatial variations of ecosystem components, and will benefit from adding spatially-explicit modelling capabilities. Another aspect that NexSym could be enhanced in is that of incorporating uncertainties in modelling, which is particularly important for supporting longterm decisions. Given the multi-scale nature of the WEF nexus challenge, it would be interesting to develop approaches to connecting a tool focusing on detailed assessment at the local level, such as NexSym, with tools that address other levels, to align the studies of the WEF nexus at different resolutions. Finally, the current version of NexSym has focused on resource consumption and environmental impacts, while there are a range of economic and social aspects that need to be considered when evaluating the viability of a local FEW system, which are yet to be added to the tool.

\section{Conclusions}

Addressing the needs for integrated tools for understanding and assessing the water-energyfood nexus at the local scale, this research presented a new simulation and analytics framework, which materialised in a new nexus simulation tool, NexSym. One novel aspect of the tool involves the scope for simulation and analysis by including ecosystem and consumption components to capture temporal dynamics, while enabling incorporation of input-output models of specific local technological components for food, energy and water supply. The second novel aspect is the capability to explore and assess potential synergies between ecological and technological components and between different technological components, for achieving more efficient resource utilisation and a better balance between demand and supply within a local system. These two novel aspects allow the users to incorporate details particularly available at the local scale, and gain holistic insights into not only the interdependencies but also the dynamics in the techno-ecological system and the opportunities of better designing or managing the WEF nexus. NexSym allowed assessment of the synergistic design of a local nexus system in a UK eco-town. It was found that the design improved local nutrient balance and meets $100 \%$ of electricity demand, while achieving higher carbon capture and biomass provisioning, higher water reuse and food production, however with a remarkable impact on land use.

NexSym is particularly useful in exploring potential improvement options before comprehensive optimisation is carried out, or for validating and analysing specific optimisation 
results within a wider context of a local system. As a tool primarily for studying local systems, NexSym requires sufficient details of a locale to allow meaningful assessments to be carried out. Engagement with researchers and local communities to develop datasets specific to local contexts is crucial for the successful application of the tool. A copy of the NexSym software tool presented is available from the authors upon request.

\section{Acknowledgements}

This work was supported by the Leverhulme Trust [grant number RPG-2012-663].

The Whitehill and Bordon eco-town is also acknowledged for the information supplied to develop the case study.

\section{References}

[1] McKinsey \& Company. Charting Our Water Future. Economic frameworks to inform decision-making. 2009.

[2] IEA. World Energy Outlook. 2012.

[3] FAO. World Agriculture Towards 2030/2050: The 2012 Revision. Rome: 2012.

[4] Machell J, Prior K, Allan R, Andresen JM. The water energy food nexus - challenges and emerging solutions. Environ Sci Water Res Technol 2015;1:15-6. doi:10.1039/C4EW90001D.

[5] IEA. Water for Energy: Is energy becoming a thirstier resource? 2012.

[6] UNESCO-IHE, Institute for Water Education. Water, Food \& Energy Security 2013. https://www.un-ihe.org/research-themes/water-food-energy-security.

[7] Liu Y, Hejazi M, Kyle P, Kim SH, Davies E, Miralles DG, et al. Global and regional evaluation of energy for water. Environ Sci Technol 2016:acs.est.6b01065. doi:10.1021/acs.est.6b01065.

[8] Hoff H. Understanding the Nexus. Background Paper for the Bonn2011 Conference: The Water, Energy and Food Security Nexus. Stockholm: 2011.

[9] Chang Y, Li G, Yao Y, Zhang L, Yu C. Quantifying the water-energy-food nexus: Current status and trends. Energies 2016;9:1-17. doi:10.3390/en9020065.

[10] Liu J, Mooney H, Hull V, Davis SJ, Gaskell J, Hertel T, et al. Systems integration for global sustainability. Science (80- ) 2015;347:1258832. doi:10.1126/science.1258832.

[11] Endo A, Tsurita I, Burnett K, Orencio PM. A review of the current state of research on the water, energy, and food nexus. J Hydrol Reg Stud 2015. doi:10.1016/j.ejrh.2015.11.010.

[12] Howarth C, Monasterolo I. Understanding barriers to decision making in the UK energyfood-water nexus: The added value of interdisciplinary approaches. Environ Sci Policy 2016;61:53-60. doi:10.1016/j.envsci.2016.03.014.

[13] DOE Water Energy Nexus Report June 2014 n.d. 
[14] Elobeid A, Tokgoz S, Dodder R, Johnson T, Kaplan O, Kurkalova L, et al. Integration of agricultural and energy system models for biofuel assessment. Environ Model Softw 2013;48:1-16. doi:10.1016/j.envsoft.2013.05.007.

[15] Khan Z, Linares P, Rutten M, Parkinson S, Johnson N, García-González J. Spatial and temporal synchronization of water and energy systems: Towards a single integrated optimization model for long-term resource planning. Appl Energy 2017; In Press. doi:10.1016/j.apenergy.2017.05.003.

[16] Irabien A, Darton RC. Energy-water-food nexus in the Spanish greenhouse tomato production. Clean Technol Environ Policy 2016;18:1307-16. doi:10.1007/s10098-0151076-9.

[17] Ermolieva TY, Ermoliev YM, Havlik P, Mosnier A, Leclere D, Kraksner F, et al. Systems Analysis of Robust Strategic Decisions to Plan Secure Food, Energy, and Water Provision Based on the Stochastic Globiom Model. Cybern Syst Anal 2015;51:125-33. doi:10.1007/s10559-015-9704-2.

[18] Adnan H. Water , Food and Energy Nexus in Asia and the Pacific 2013:72.

[19] Daher BT, Mohtar RH. Water-energy-food (WEF) Nexus Tool 2.0: guiding integrative resource planning and decision-making. Water Int 2015;40:1-24. doi:10.1080/02508060.2015.1074148.

[20] White DJ, Hubacek K, Feng K, Sun L, Meng B. The Water-Energy-Food Nexus in East Asia: A tele-connected value chain analysis using inter-regional input-output analysis. Appl Energy 2017. doi:10.1016/j.apenergy.2017.05.159.

[21] Karnib A. A Quantitative Assessment Framework for Water, Energy and Food Nexus. Comput Water, Energy, Environ Eng 2017;6:11-23. doi:10.4236/cweee.2017.61002.

[22] Giampietro M, Mayumi K, Ramos-Martin J. Multi-scale integrated analysis of societal and ecosystem metabolism (MuSIASEM): Theoretical concepts and basic rationale. Energy 2009;34:313-22. doi:10.1016/j.energy.2008.07.020.

[23] Schlör H, Venghaus S, Hake J-F. The FEW-Nexus city index - Measuring urban resilience. Appl Energy 2017. doi:10.1016/j.apenergy.2017.02.026.

[24] Li G, Huang D, Li Y. China's input-output efficiency of water-energy-food nexus based on the data envelopment analysis (DEA) model. Sustain 2016;8. doi:10.3390/su8090927.

[25] Howells M, Hermann S, Welsch M, Bazilian M, Segerström R, Alfstad T, et al. Integrated analysis of climate change, land-use, energy and water strategies. Nat Clim Chang 2013;3:621-6. doi:10.1038/nclimate1789.

[26] Kraucunas I, Clarke L, Dirks J, Hathaway J, Hejazi M, Hibbard K, et al. Investigating the nexus of climate, energy, water, and land at decision-relevant scales: the Platform for Regional Integrated Modeling and Analysis (PRIMA). Clim Change 2015;129:57388. doi:10.1007/s10584-014-1064-9.

[27] Endo A, Burnett K, Orencio PM, Kumazawa T, Wada CA, Ishii A, et al. Methods of the water-energy-food nexus. Water (Switzerland) 2015;7:5806-30. doi:10.3390/w7105806. 
[28] Mannschatz T, Wolf T, Hulsmann S. Nexus Tools Platform: Web-based comparison of modelling tools for analysis of water-soil-waste nexus. Environ Model Softw 2016;76:137-53. doi:10.1016/j.envsoft.2015.10.031.

[29] Hussien WA, Memon FA, Savic DA. An integrated model to evaluate water-energyfood nexus at a household scale. Environ Model Softw 2017;93:366-80. doi:10.1016/j.envsoft.2017.03.034.

[30] Martinez-Hernandez E, Leung Pah Hang MY, Leach M, Yang A. A Framework for Modeling Local Production Systems with Techno-Ecological Interactions. J Ind Ecol 2016;0. doi:10.1111/jiec.12481.

[31] Leung Pah Hang MY, Martinez-Hernandez E, Leach M, Yang A. Designing integrated local production systems: A study on the food-energy-water nexus. J Clean Prod 2016;135:1065-84. doi:10.1016/j.jclepro.2016.06.194.

[32] Garcia DJ, You FQ. The water-energy-food nexus and process systems engineering: A new focus. Comput Chem Eng 2016;91:49-67. doi:10.1016/j.compchemeng.2016.03.003.

[33] Bakshi BR, Ziv G, Lepech MD. Techno-ecological synergy: A framework for sustainable engineering. Environ Sci Technol 2015;49:1752-60. doi:10.1021/es5041442.

[34] Martinez-Hernandez E, Leach M, Yang A. Impact of bioenergy production on ecosystem dynamics and services-a case study on U.K. heathlands. Environ Sci Technol 2015;49:5805-12. doi:10.1021/es505702j.

[35] Yuling M, Pah L, Martinez-hernandez E, Leach, Matthew, Yang A. An insight-based approach for the design of integrated local food-energy-water systems. 2017. 